\title{
Three Siblings with Asperger Syndrome: A Family Case Study
}

\author{
N. Ghaziuddin, L. Metler, M. Ghaziuddin, ${ }^{*}$ L. Tsai and B. Giordani ${ }^{*}$
}

Reports of multiple incidence of Asperger syndrome have suggested links between Asperger syndrome and autism. In this case study, we describe three siblings with Asperger syndrome based on the ICD-10 criteria. There was no family history of mental retardation or of autism. We propose that in some families, Asperger syndrome may occur as a distinct clinical entity and show no overlap with autism.

Asperger syndrome (AS; Asperger, 1944) is a developmental disorder widely regarded as a variant of autism. Opinion is divided about the extent to which it differs from autism. Asperger believed that it was a distinct disorder that was genetically transmitted. He reported that the characteristics tended to occur in families, particularly in fathers (Wing, 1981). In Wing's series of 34 cases, 5 out of 16 fathers and 2 out of 24 mothers showed behaviour resembling that found in Asperger syndrome.

Although there are many reports of multiple incidence of autism among siblings, similar studies of siblings with AS are few. Burgoine and Wing (1983) described a set of identical triplets with AS. Since some of the features were more typical of autism, the authors presented this as further evidence in support of their view that autism and AS are closely related. Earlier, Van Krevelen (1971) described the presentation of AS and autism in one each of two members of the same family. One of the children in a family of three had the features of AS, while the youngest was diagnosed as suffering from autism. Bowman (1988) described a family in which the father probably had AS. One of the four sons had AS; two had autism; and one was normal. In a series of studies on children diagnosed as suffering from 'schizoid' personality, thought to be similar to those described by Asperger, Wolff and colleagues found increased prevalence of 'schizoid' traits in the parents (Wolff et al., 1988; Narayan et al., 1990). More recently, Gillberg (1991) described the clinical and neuro- biological aspects of Asperger syndrome in six family case studies; many of the families showed a variety of autistic-like disorders ranging from 'Asperger traits' to autism. This, again, was presented as evidence in support of the hypothesis that autism and AS share common feartures and are closely related.

Operational criteria were not used for the diagnosis of AS in most of the above studies. In addition, there are no published reports of AS occurring in all the siblings of a family other than the one reported by Burgoine and Wing (1983). In this paper, the authors describe the presentation of the syndrome in three siblings using the ICD-10 (WHO, 1987) criteria for diagnosis.

\section{Case Histories:}

$\mathrm{MH}$

$M$, aged 15 years, was referred for behavioural problems. He was born after a full term normal delivery. He sat at 7 months and walked at 9 months of age. His speech and language development was normal. He spoke single words well before the age of 2 years and sentences by three years. As he grew up, he was found to lack interest in other children and to prefer solitary activities. In his first grade at school, he was classified as emotionally impaired, and placed in a class-room for

* Dept of Child Psychiatry, Psych Annex Box 0290, University of Michigan Hospital, 200 East Hospital Drive, Ann Arbor, MI 48109-0290, USA. Correspondence to M. Ghaziuddin. 
emotionally impaired children. As his academic performance was in the superior range, he was transferred back to a regular class-room in his fifth grade. He was referred for psychiatric evaluation at the age of six years and was treated with individual psychotherapy. Because of persistent social difficulties and problems of interaction with peers, he was re-evaluated at the age of 10 years and given a diagnosis of autism. Despite his social problems, he continued to be a bright student, achieving $A$ and $B$ grades. However, he had no friends. His main activity outside school consisted of playing with his computer and reading books on science. He had a great interest in numbers, and liked working on the various combinations of the digit 7. At times, he indulged in long monologues on the importance of this digit. He believed that there were seven heavens just as there were. seven levels of energy. His interest in science occasionally led him to perform experiments, some of which were rather difficult to understand. For example, he once tried to collect water from a sink into a small bottle, and believed that it was possible to do so by magnetism. He was frequently teased by his class-mates. For example, he would lick milk off a plate when asked to do so by other children. In addition, he was markedly clumsy. $\mathrm{He}$ walked with an awkward gait, and, according to his mother, learned to tie his shoe-laces only when he was 13 years old. His medical history was negative.

The presenting symptoms at the time of this referral consisted of persistent hand-washing and irritability of about six months' duration. His sleep and appetite were also disturbed. He would wash hands as often as he could, to the extent that the skin had started peeling. He said he was afraid of both catching and giving germs to other people and felt guilty about depriving other people of their share of toilet paper. He tried to stop himself from washing his hands and also worrying about germs, but felt unable to do so.

On psychiatric examination, he looked aloof and withdrawn. He made no eye contact throughout the interview. He spoke in a low monotonous voice with little inflection, but appeared animated while talking about science and numbers. $\mathrm{He}$ showed a preoccupation with minute details; for example, when asked how far he lived, he became visibly anxious trying to give the exact distance in miles. He showed a similar preoccupation with other details; for example, when describing a situation where he was cornered by his class-mates, he was unable to describe what had actually happened; instead, he got preoccupied with the number of corners the room had! He denied any persistently depressed mood or any suicidal ideas. He admitted, however, that he washed hands repeatedly and was preoccupied with dirt. There was no evidence of any auditory or visual hallucinations. $\mathrm{He}$ was well-oriented in time, place and person. His physical examination was normal.

On the Wechsler Intelligence Scale for Children-Revised (WISC-R, 1974), his Verbal IQ was 105; Performance IQ 91; and Full scale IQ was 91. On the Facial Recognition Test (FRT; Benton et al., 1983), which is a measure of recognition of unfamiliar faces, he was severely impaired. On the Category Test (CT; Reitan \& Davison, 1974; Spreen \& Strauss, 1991), which reflects such problem solving skills as abstraction, concept formation, and mental flexibility, he was mildly impaired; while on the Continuous Performance Test (CPT; Loong, 1988), which is a sensitive test for assessing sustained attention and mental lapses, he scored within the normal range. On the Autism Behaviour Checklist (Krug et al., 1980), he was given a score of 74 by mother and 43 by father.

Based on the above history and the mental status examination, he was given a DSM-III-R (1987) diagnosis of Obsessive-Compulsive Disorder on Axis I and Pervasive Development Disorder Not Otherwise Specified (PDDNOS) on Axis II. On the autism symptom checklist of the DSM-III-R, he met the following five criteria: markedly abnormal social play; gross impairment in the ability to make peer friendships; abnormal nonverbal communication; impaiment in the ability to sustain conversation; and a markedly restricted range of interests. The diagnosis of Asperger syndrome was based on the ICD-10 criteria as follows: lack of any clinically significant general delay in language or cognitive development; qualitative impairment in reciprocal social interaction as in autism; and a restricted pattern of interests and behaviour. The presence of clumsiness, although not an established feature of the syndrome (Ghaziuddin et al., 1992), further supported the diagnosis.

\section{$\mathrm{SH}$}

$\mathrm{S}$ is the second son. He is 13 years old and is in regular education.

Developmental history revealed an uneventful pregnancy and delivery. His speech and language 
development was normal. He spoke single words by the age of one year, sentences by two years and could read by the age of about 4 years. No major problems in communication or social interaction were noted before three years of age. Around the age of 4 years, he came to the attention of school authorities because of problems with social interaction and was diagnosed as "autistic". He never participated in any play with his peers and preferred to stay by himself. He had an odd way of communicating with others. He seldom looked at his listener, and occasionally repeated the words of others. He was fascinated by spinning objects and liked spinning himself. Sometimes, he walked on his toes. His main interest, which constantly distracted him, was preoccupation with numbers. He would spend hours working on numbers; sometimes he carried a note-book while at other times, he worked on a number-puzzle. Besides, he was poor at fine motor movements and could not tie his shoe-laces properly. He was receiving physical therapy for poor coordination when seen by the authors.

At the time of interview, he was of average height and appeared his stated age. He hardly looked at the examiner and sat opening and shutting a number-game. He spoke in a monotonous voice and said that he enjoyed doing math. However, unlike his brother, he showed no tendency to indulge in long one-sided conversations on his interests. Also, he showed no evidence of any disturbance of mood or of thought. On psychological testing, he scored a Full Scale IQ of 91 . His Performance IQ was 100 and his Verbal IQ was 86. He was rated below average on the FRT; above average on the CT and normal on the CPT. On the Autism Behaviour Checklist, he was given the scores of 35 by mother and 45 by father respectively. He scored only 3 of the 16 items of the DSM-III-R symptom check-list for autistic disorder at the time of the interview, and therefore, qualified for a diagnosis of PDDNOS. These were: marked lack of awareness of the feelings or existence of others; gross impairment in the ability to make peer friendships; and impairment in the ability to initiate or maintain conversation. However, when he was examined on the basis of the ICD-10 criteria, he too met the criteria for Asperger syndrome. This was because of the presence of autistic social dysfunction without language or cognitive impairment. Like his older brother, he too seemed to suffer from clumsiness, which further supported the diagnosis.
$J H$

$\mathrm{J}$, aged 9 years, is the youngest son. He is also in regular education, and, like his older brothers, is regarded as a bright student.

Developmental history revealed that he was delivered by face presentation after a normal pregnancy. His speech and language development was normal. He spoke single words by one year and sentences by two years. His motor milestones were also reached within the normal range. He sat at six months and walked without support at one year. Nothing abnormal was detected till he started school. He could not make friends easily and preferred to play with himself. He was evaluated by school authorities and given a diagnosis of "autism". His medical history was not significant. He too had difficulty in initiating conversation, although his eye contact was described as being marginally better than that of his older brothers. Also, unlike his brothers, he was described by his mother as being a better judge of the feelings of others.

Apart from the problems of social interaction, which were not as severe as in the case of the other two brothers, his main problem was also preoccupation with numbers. He counted almost everything. He preferred to sit by himself playing with number-games. Although he was a good student, he needed to be watched closely at school, because of his tendency to start working with numbers. Apart from this, he showed no other rituals or preoccupations and was not unduly disturbed by a change of routines. He denied any disturbance of mood or the presence of intrusive thoughts. However, like his older brothers, he too had a difficulty with fine motor tasks. At the time of the referral, he could not tie his shoe-laces properly and was in physical therapy.

At interview, he showed limited eye contact. He carried a note-book with numbers written in it. There was no disturbance of mood or of perception. On the WISC-R, his Verbal IQ was 136; Performance IQ was 149; and his Full Scale IQ was 146. On the Autism Behaviour Checklist, he was given the scores of 16 by father and 46 by mother respectively. On the FRT, he was marked as average; on the CT as above average; and on the CPT as normal. Based on mother's account and the clinical observation, he scored on four items out of the 16 given in the DSM-III-R autistic disorder symptom checklist at the time of the interview. These 4 items were: gross impairment 
in the ability to make peer-relationships; marked inability to initiate or maintain conversation; a restricted range of interests; and a preoccupation with certain objects such as number-games. He, therefore, did not meet the required number of criteria for a DSM-III-R diagnosis of autistic disorder. However, he met the ICD-10 criteria for Asperger syndrome based on a history of normal language development; lack of cognitive delay; a qualitative impairment in reciprocal social interaction as in autism; a restricted range of interests and activities; and the presence of clumsiness.

\section{$\mathrm{KH}$}

$\mathrm{K}$, aged 7 years, is the youngest child. She is a first grade student. She was born after a normal preg-. nancy by a Caesarian section as a result of foetal distress. Her motor and language milestones were reached in time. There was no significant medical or surgical history. She behaved appropriately at school, although she was said to have occasional problems in attention and concentration. Her play was described as socially appropriate. At interview, she was pleasant and cooperative. Her eye contact was appropriate; and so was her speech and behaviour. Her Full Scale IQ was 103; Verbal IQ was 108; and Performance IQ was 98. On the FRT, she scored in the average range; on the $C T$, in the above average range; but was marked below average on the $\mathrm{CPT}$, reflecting an impairment in attention. Based on the above findings, she did not meet the DSM-III-R criteria for a pervasive developmental disorder.

\section{Mr H (Father)}

$\mathrm{Mr} \mathrm{H}$, aged 45 years, is a computer analyst. His birth and early childhood were apparently normal. $\mathrm{He}$ has two years of college education. There is no family or past history of psychiatric illness. However, he has two unmarried sisters, both in their fifties, who are described as extremely isolative and withdrawn. Watching television and working on his computer are his main hobbies. According to his wife, he has never had a close friend. He has been married for 18 years and describes his marriage as happy. However, he does not speak much at home. He never loses his temper and does not appear irritable or sad. At interview, his eye contact was appropriate. There was no abnormality of speech. He did not appear clinically depressed, nor was there any defect of thought or of cognition. However, because of his pervasive pattern of indifference to social relationships and a restricted range of emotional experience and expression, he met the DSM-III-R criteria for schizoid personality disorder (APA, 1987). On the Wechsler Adult Intelligence Scale (WAISR, 1981), his Full Scale IQ was 110; Verbal IQ was 116 and Performance IQ was 101 . He scored in the average range on the FRT, and normal on the CT and the CPT.

\section{Mrs H (Mother):}

Mrs $\mathrm{H}$, aged 43 years, is a housewife. She denied any past or family history of psychiatric illness. She trained as a nurse and worked till her second child was born. She said that she enjoyed the company of other people, and described herself as a social person. Her mental status examination was not significant. On the WAIS-R, her Verbal, Performance and Full Scale IQ was 93 . Her scores on the other tests (CT; FRT; and CPT) were also normal.

\section{Discussion}

None of the three brothers met the DSM-III-R criteria for autistic disorder or the ICD-10 criteria for autism. Also, on the Autism Behaviour Checklist, which gives standardized scores in a variety of areas including social relatedness and communication, and which has been used to differentiate autistic children from normal and mentally handicapped children (Krug et al., 1980), their scores fell below the autistic range. However, all of them met the ICD-10 criteria for Asperger syndrome. They all showed the social impairment of autism with normal intelligence and a normal history of language development. In addition, they all suffered from a significant degree of clumsiness, which further supported the ICD-10 diagnosis of Asperger syndrome (WHO, 1987). As shown in Table 1, a Verbal-Performance IQ discrepancy was present in only one patient (Patient $M$ ), while the two younger brothers showed no such discrepancy. On the other hand, the sister $\mathrm{KH}$, also showed a Verbal Performance IQ split (VIQ=108; $P I Q=98$ ) but showed no features suggestive of Asperger syndrome. These results are consistent 
Table 1. Comparison of neuropsychological findings of the siblings and the parents.

\begin{tabular}{|c|c|c|c|c|c|c|}
\hline & $M, 15$ & $S, 13$ & $\mathrm{~J}, 9$ & $\mathrm{~K}, 7$ & $\mathrm{Mr} \mathrm{H}, 45$ & Mrs H, 43 \\
\hline FSIQ & 91 & 91 & 146 & 103 & 110 & 93 \\
\hline VIQ & 105 & 86 & 136 & 108 & 116 & 93 \\
\hline PIQ & 91 & 100 & 149 & 98 & 101 & 93 \\
\hline FRT & SI & $\begin{array}{l}\text { Below } \\
\text { average }\end{array}$ & Average & Average & Average & $\begin{array}{l}\text { High } \\
\text { average }\end{array}$ \\
\hline Category Test & $\begin{array}{l}\text { Mild } \\
\text { impair }\end{array}$ & $\begin{array}{l}\text { Above } \\
\text { average }\end{array}$ & $\begin{array}{l}\text { Above } \\
\text { average }\end{array}$ & $\begin{array}{l}\text { Above } \\
\text { average }\end{array}$ & Normal & Normal \\
\hline $\mathrm{CPT}$ & Normal & Normal & Normal & $\begin{array}{l}\text { Below } \\
\text { average }\end{array}$ & Normal & Normal \\
\hline $\begin{array}{l}\text { Psychiatric } \\
\text { diagnosis }\end{array}$ & $\begin{array}{l}\text { AS and } \\
O C D\end{array}$ & AS & AS & $\begin{array}{l}\text { No } \\
\text { diagnosis }\end{array}$ & $\begin{array}{l}\text { Schizoid P } \\
\text { disorder }\end{array}$ & $\begin{array}{l}\text { No } \\
\text { diagnosis }\end{array}$ \\
\hline
\end{tabular}

AS: Asperger Syndrome

FSIQ: Full scale IQ; VIQ: Verbal IQ; PIQ: Performance IQ

FRT: Facial Recognition Test

CPT: Continuous Performance Test

SI: Severely Impaired

OCD: Obsessive-Compulsive Disorder

with those of other studies which have suggested that the VIQ/PIQ split seems to favour PIQ in High Functioning Autistic persons but does not appear to be as evident in patients with Asperger syndrome (Ozonoff et al., 1991). On the Category Test, which is a sensitive neuropsychological measure of organic brain damage (Spreen \& Strauss, 1991), but does not identify specific diagnostic groups, the three brightest children in the family had above average scores. This probably reflects their higher IQ scores as these are reported to be comelated with performance on the Category Test (Spreen \& Strauss, 1991).

Some reports have found increased prevalence of Asperger syndrome in families of patients with high-functioning autism. Thus, DeLong and Dwyer reported that in over two thirds of families with a high-functioning autistic child, a first or second degree relative had Asperger syndrome, while in the families of autistic children with an IQ less than 70 , only $6.2 \%$ had such an affected relative (DeLong \& Dwyer, 1988). Other studies have found increased prevalence of AS or 'Asperger traits' in parents of AS children (see Gillberg, 1991).

Several reports have suggested that like autism, Asperger syndrome may also run in families. Social and communication deficits, similar to those occurring in AS, appear to be common in the families of patients with this syndrome (Asperger, 1944; Gillberg, 1991). For example, Van Krevelen suggested that AS was transmitted genetically via the father, and remarked that "many of the patients' fathers, in spite of their unusual personality traits, held eminent social positions" (Van Krevelen,
1971). In Van Krevelen's paper, the father, a 47 year old man, was also odd and eccentric. He hung a copper plate with his academic degrees in his. home study and insisted on being addressed accordingly. He was rational but rigid and had a great difficulty in showing tact and sensitivity. In the present report as well, the father was described as aloof and rigid. He had no friends and interacted more with computers than with people. He did not appear to enjoy close relationships including being part of the family. His wife described him as odd and socially aloof. Thus, based on this information, he met the DSM-III-R criteria for schizoid personality disorder. This finding is consistent with other studies which have found the presence of schizoid traits and schizoid personality disorder in parents of children with "well-functioning autism", some of whom are thought to be similar to the children described by Asperger (Wolff et al., 1988; Narayan et al., 1990).

Despite the confusion surrounding the diagnosis of AS, it is generally agreed that the syndrome has overlapping features with autism. Reports that have described the occurrence of AS and autism in members of the same family (Van Krevelen, 1971; Bowman, 1988) lend some support to the theory of "autistic continuum". According to this hypothesis, autism and Asperger syndrome can be conceptualized as lying on a continuum of severity with.Asperger syndrome representing a mild form of autism (Wing, 1981). The present case study differs from the others in that, all the three affected members showed features consistent with a diagnosis of Asperger syndrome, and that neither the parents nor the unaffected sibling met the criteria 
for autism. While this observation does not necessarily constitute evidence against the "continuum hypothesis" of autism, it does suggest that, at least in some families, AS may occur in a pure form without showing an overlap with autism. Large-scale epidemiological studies of Asperger syndrome, especially of families with multiple cases, are needed to delineate the differences and the similarities between this disorder and autism.

\section{Résumé}

Les publications sur l'incidence multiple du Syndrome d'Asperger ont suggéré des liens entre ce syndrome et l'autisme. Dans cette étude, nous décrivons 3 membres d'une même fratrie avec un Syndrome d'Asperger répondant aux critères. d'l'ICD-10. Il n'y avait pas dans l'histoire familiale de retard mental ni d'autisme. Nous proposons que dans certaines familles le Syndrome d'Asperger peut survenir comme entité clinique distincte sand chevauchement avec l'autisme.

\section{Zusammenfassung}

Berichte über multiples Auftreten des AspergerSyndroms haben Zusammenhänge zwischen dem Asperger-Syndrom und Autismus nahegelegt. In diesem Fallbericht beschreiben wir drei Geschwister mit einem Asperger-Syndrom (ICD-10-Kriterien). Die Familienanamnese in Hinblick auf geistige Behinderung oder Autismus war unauffällig. Wir schlagen vor, da $B$ in einigen Familien das Asperger-Syndrom als eine eigenständige klinische Entität ohne Überlappung zum Autismus auftreten kann.

\section{References}

American Psychiatric Association (1987). Diagnostic and Statistical Manual (3rd ed., rev). Washington, DC: Author.

Asperger, H. (1944). Die 'autistischen Psychopathen' im Kindesalter. Archiv fur Psychiatrie und Nervenkrankheiten, 117, 76-136.

Benton, A.L., Hamsher, K. deS., Varney, N.R. \& Spreen, O. (1983). Test of recognition of unfamiliar faces. In Contributions to Neurolpsychological Assessment. New York: Oxford University Press.

Bowman, E.P. (1988). Asperger's syndrome and Au- tism: The case for a connection. British Journal of $P_{s \gamma-}$ chiatry, 152, 377-382.

Burgoine, E. \& Wing, L. (1983). Identical triplets with Aspeger's syndrome. British Joumal of Psychiatry, 143, 261-265.

DeLong, G.R. \& Dwyer, J.T. (1988). Correlation of family history with specific autistic subgroups: Asperger's syndrome and Bipolar Affective Disease. Joumal of Autism and Developmental Disorders, 18, 593600.

Ghaziuddin, M., Tsai, L.Y. \& Ghaziuddin, N. (1992). A reappraisal of clumsiness as a diagnostic feature of Asperger syndrome. Joumal of Autism and Developmental Disorders (in press).

Gillberg, C. (1991). Clinical and neurological aspects of Asperger syndrome in six family studies. In U. Frith (Ed.), Autism and Asperger Syndrome. Cambridge: Cambridge University Press.

Krug, D.A., Arick, J. \& Almond, P. (1980) Behavior checklist for identifying severely handicapped individuals with high levels of autistic behavior. Joumal of Child Psychology and Psychiatry, 21, 221-229.

Loong, J. (1988). The Continuous Pefformance Test. San Louis Obispo, CA: Wang Neuropsychological Laboratory.

Narayan, S., Moyes, B. \& Wolff, S. (1990). Family characteristics of autistic children: A further report. Joumal of Autism and Developmental Disorders, 20, 523535.

Ozonoff, S., Rogers, S.J. \& Pennington, B.F. (1991). Asperger's syndrome: Evidence of an empirical distinction from High-Functioning Autism. Joumal of Child Psychology and Psychiatry, 32, 1107-1122.

Reitan, R.M. \& Davison, L.A. (1974). Neuropsychology: Current Status and Applications. Washington, D.C.: Winston \& Sons.

Spreen, O. \& Strauss, E.A. (1991). A Compendium of Neuropsychological Tests. New York: Oxford University Press.

Van Krevelen, D.A. (1971). Early infantile autism and autistic psychopathy. Joumal of Autism and Childhood Schizophrenia, 1, 82-86.

Wechsler, D. (1974). Wechsler Intelligence Scale for Children-Revised. New York: The Psychological Corporation.

Wechsler, D. (1981). Wechsler Intelligence Scale for Adults. New York: The Psychological Corporation.

Wing, L. (1981). Asperger's syndrome: A clinical account. Psychological Medicine, 11, 115-129.

Wolff, S., Narayan, S. \& Moyes, B. (1988). Personality characteristics of parents of autistic children: A controlled study. Journal of Child Psyhology and Psychiatry, 29, 143-153.

World Health Organization (1987). Intemational Classification of Diseases (10th rev.). Geneva: Author. 